\title{
The Effect of Thermo-Mechanical Processing on Physical Properties of Processed Amaranth and Oat Bran Composites
}

\author{
Sean X. Liu ${ }^{1}$, Diejun Chen ${ }^{1}$, George E. Inglett ${ }^{1} \&$ Jingyuan $\mathrm{Xu}^{2}$ \\ ${ }^{1}$ Functional Food Research Unit, National Center for Agricultural Utilization Research, USDA-ARS. $1815 \mathrm{~N}$ \\ University Street, Peoria, IL 61604, USA \\ ${ }^{2}$ Plant Polymer Research Unit, National Center for Agricultural Utilization Research, USDA-ARS. $1815 \mathrm{~N}$ \\ University Street, Peoria, IL 61604, USA \\ Correspondence: Sean X. Liu, Functional Food Research Unit, National Center for Agricultural Utilization \\ Research, USDA-ARS. 1815 N University Street, Peoria, IL 61604, USA. Tel: 1-309-681-6551. E-mail: \\ Sean.liu@ars.usda.gov
}

Received: January 25, 2017 Accepted: February 28, 2017 Online Published: March 8, 2017

doi:10.5539/jfr.v6n2p82 URL: https://doi.org/10.5539/jfr.v6n2p82

\begin{abstract}
Amaranth-oat composites were developed using gluten free amaranth flour containing essential amino acids and minerals with oat products containing $\beta$-glucan, known for lowering blood cholesterol. Amaranth flour and oat bran concentrate (OBC) composites (1:4) were processed using different technologies, including dry mixing, baking, steaming, cold wet blending, and high speed homogenizing (Polytron PT6000) with cold water or hot water. The results showed that water holding capacities, pasting, and rheological properties were dramatically increased by wet blending, Polytron with cold water, and Polytron with hot water followed by drum drying. The processing procedures created dissimilar physical properties that will enhance the application of ancient grains and oat for functional foods that are suitable for people who are gluten-intolerant. In addition, the dietary fiber contents of composites were increased by the incorporation of OBC. The composites can be inexpensively prepared and processed. The new healthful products will be affordable for people who suffer from celiac disease or gluten-intolerant. These innovative gluten-free functional food products will help millions of gluten sensitive consumers enjoy heart-healthy functional foods.
\end{abstract}

Keywords: amaranth, oat, pasting, rheology

\section{Introduction}

Amaranth (amaranthus caudatus) grains contain about thirty percent more protein than cereals like rice, sorghum and rye (Macvean \& Pöll, 1997). Amaranth grains are important nutritional sources of thiamine, niacin, riboflavin, and folate, and dietary minerals including calcium, iron, magnesium, phosphorus, zinc, copper, and manganese that are comparable to common grains such as wheat germ, oats and others; amaranth flour also has an unusually rich source of the essential amino acid lysine that is low in other grains (Myers \& Putnam, 1988; USDA, 2014). Unlike the protein found in wheat and rye, amaranth contains a promising source of protein for people that are sensitive to gluten since it is gluten free (USDA, 2014). Amaranth has valuable nutrient contents for gluten-free diets compared to buckwheat, corn, millet, wild rice, oats and quinoa (Gallagher et al., 2004). In addition, amaranth seed oil may be of benefit for those with hypertension and cardiovascular disease. Moreover, regular consumption of amaranth reduces blood pressure and cholesterol levels while improving antioxidant status and some immune parameters (Czerwiński et al., 2004; Martirosyan et al., 2007). Amaranth flour has been evaluated as a supplement to wheat flour. The different levels of amaranth flour were mixed with wheat flour and baking ingredients that were fermented, molded, pan-proved and baked. The loaf volume decreased with increasing amounts of amaranth grain flour. Loaf volumes were significantly decreased for breads containing over15\% amaranth flour compared to wheat flour bread on sensory qualities (Ayo, 2001).

Although amaranth has excellent nutritional value, it has low viscosity in contrast to oats that have high viscosity and water holding capacity. Oat products, such as whole oat flour (WOF) and oat bran concentrate (OBC), contain $\beta$-glucan that has beneficial health effects on reducing serum cholesterol and postprandial serum glucose levels (Klopfenstein, 1988). In addition, the phenolic and other antioxidant compounds in oat provide health benefits (Madhujith \& Shahidi, 2007; Inglett et al., 2011; Inglett \& Chen, 2012). Oat hydrocolloid products 
containing $\beta$-glucan have numerous functional food applications to reduce fat content and calories in a variety of foods (Lee et al., 2004); control the rheology and texture of food products (Rosell et al., 2001); modify starch gelatinization and retrogradation (Lee et al., 2005); and also provide freezing/thawing stability (Lee et al., 2002). Rheological and physiochemical evaluations of jet-cooked oat bran have been studied in low calorie cookies by replacing $20 \%$ of the shortening with oat $\beta$-glucan hydrocolloids (Lee $\&$ Inglett, 2006).

Besides viscosities, amaranth flour and oat products complement each other due to their nutrition. Amaranth grains are short of some essential amino acids, such as leucine and threonine (Bressani et al., 1989; Kaufmann \& Weber, 1990) whereas these are abundant in oats (Pisarikova et al., 2006). Thus, oat products were used to produce composites containing $\beta$-glucan in combination with amaranth's distinctive protein profile along with its gluten free uniqueness.

Although amaranth and oat composites were studied previously (Inglett et al., 2014), the information on processed amaranth and oat composites were not scientifically studied and reported. In this exploratory study, the amaranth-oat composites (1:4) were processed using different technologies, and their physical properties were evaluated. The objectives of this study were to develop innovative amaranth-oat composites using different technologies that keep the original physical and nutritional values; and to find effect of thermo-mechanical processing on physical properties of composites. The physical properties of processed amaranth-oat composites using different technologies could provide useful information for new functional food products.

\section{Materials and Methods}

\subsection{Ingredients}

Organic gluten free amaranth flour was purchased from Dakota Prairie Organic Flour Co. Harvey, ND, USA. Oat bran concentrate (OBC) was supplied by Quaker Oats (Chicago, IL, USA).

\subsection{Processing Procedures}

Treatment 1: dry mixing. The amaranth-oat composite was prepared by combining amaranth flour with $20 \%$ OBC. The amaranth flour $(960 \mathrm{~g})$ was mixed with $20 \%$ (w/w) OBC (240 g) for 5 min using a wire whip (K5AWW) by a Kitchen Aid mixer (Benton Harbor, MI) to obtain a dry blended composite, and passed through a 50 mesh screen.

Treatment 2: baking. Amaranth-oat composite ( $200 \mathrm{~g})$ from treatment 1 was roasted at $375{ }^{\circ} \mathrm{C}$ for $10 \mathrm{~min}$ in a conventional oven, and then passed through a sifter with 50 mesh screen.

Treatment 3: steaming. Amaranth-oat composites $(200 \mathrm{~g})$ from treatment 1 was wrapped in cloth and steamed at $100{ }^{\circ} \mathrm{C}$ for $20 \mathrm{~min}$, passed through a sifter with 50 mesh screen, oven dried at $45^{\circ} \mathrm{C}$, and passed through a 50 mesh screen.

Treatment 4: blend with cold water. Amaranth-oat composite (200 g) from treatment 1 was added gradually and mixed in water $\left(2.5 \mathrm{~L}, 80 \mathrm{~g} \mathrm{~kg}^{-1}\right.$ solids, w/w) by a commercial heavy duty Waring blender (Model 37BL84, Dynamics Corporation of American, New Hartford, Connecticut) for $5 \mathrm{~min}$ at $3000 \mathrm{rpm}$. The collected slurries were subsequently dried on a pilot-scale double drum dryer (model 20; Drum Dryer and Flaker Company, South Bend, IN) heated with steam at $308 \mathrm{kPa}(30 \mathrm{psig})$ and $135{ }^{\circ} \mathrm{C}$. The drum dried material was ground by an IKA mill (M20, IKA ${ }^{\circledR}$ Works, Inc., NC, USA), and passed through a sifter with 50 mesh screen.

Treatment 5: Polytron with cold water. Polytron is a homogenizer that was used in this study because the rotor/stator principle of Polytron is ideal for grinding tough tissues by sonically disrupting the cells as well as mechanically. Amaranth-oat composite $(200 \mathrm{~g})$ from treatment 1 was added gradually to water $\left(2.5 \mathrm{~L}, 80 \mathrm{~g} \mathrm{~kg}^{-1}\right.$ solids, w/w) in a 4-L container while being stirred, and then sheared using a Polytron (PT6000, Kinematica AG, Littau, Switzerland) at about 3,000 rpm before increasing the rpm to about 5000 for $10 \mathrm{~min}$. The collected slurries were subsequently dried on a pilot-scale double drum dryer (model 20; Drum Dryer and Flaker Company, South Bend, IN) heated with steam at $308 \mathrm{kPa}(30 \mathrm{psig})$ and $135^{\circ} \mathrm{C}$. The drum dried material was ground by an IKA mill (M20, IKA ${ }^{\circledR}$ Works, Inc., NC, USA), and passed through a sifter with 50 mesh screen.

Treatment 6: Polytron with hot water. Amaranth-oat composite $(200 \mathrm{~g})$ from treatment 1 was added gradually to hot water at $90^{\circ} \mathrm{C}\left(2.5 \mathrm{~L}, 80 \mathrm{~g} \mathrm{~kg}^{-1}\right.$ solids, w/w $)$ in a 4-L container, and cooked at $100{ }^{\circ} \mathrm{C}$ for 5 minutes on a hot plate, and then sheared using a Polytron (PT6000, Kinematica AG, Littau, Switzerland) at about 3,000 rpm before increasing the rpm to about 5000 for $10 \mathrm{~min}$. The collected slurries were subsequently dried on a pilot-scale double drum dryer (model 20; Drum Dryer and Flaker Company, South Bend, IN) heated with steam at $308 \mathrm{kPa}(30 \mathrm{psig})$ and $135^{\circ} \mathrm{C}$. The drum dried material was ground by an IKA mill (M20, IKA ${ }^{\circledR}$ Works, Inc., NC, USA), and passed through a sifter with 50 mesh screen. 


\subsection{Water Holding Capacity (WHC)}

The WHC was determined according to a previous procedure with minor modifications (Ade-Omowaye et al. 2003). Each sample ( $2 \mathrm{~g}$, d.b. weight) was mixed with $25 \mathrm{~g}$ of distilled water and vigorously mixed for $1 \mathrm{~min}$ to a homogenous suspension using a Vortex stirrer, held for $2 \mathrm{~h}$, and centrifuged at $1,590 \mathrm{~g}$ for $10 \mathrm{~min}$. Each treatment was replicated twice. Water-holding capacity was calculated by the difference between the weight of water added and decanted on dry basis.

\subsection{Pasting Property Measurement}

The pasting properties of samples were evaluated using a Rapid Visco Analyzer (RVA-4, Perten Scientific, Springfield, IL, USA). Each sample (2.24 g d.b.) was made up to a total weight of $28 \mathrm{~g}$ with distilled water in a RVA canister $\left(80 \mathrm{~g} \mathrm{~kg}^{-1}\right.$ solids, w/w). The viscosity of the suspensions was monitored during the following heating and cooling stages. Suspensions were equilibrated at $50^{\circ} \mathrm{C}$ for $1 \mathrm{~min}$, heated to $95^{\circ} \mathrm{C}$ at a rate of $6.0^{\circ} \mathrm{C} / \mathrm{min}$, maintained at $95^{\circ} \mathrm{C}$ for $5 \mathrm{~min}$, and cooled to $50^{\circ} \mathrm{C}$ at rate of $6.0^{\circ} \mathrm{C} / \mathrm{min}$, and held at $50^{\circ} \mathrm{C}$ for $2 \mathrm{~min}$. For all test measurements, a constant paddle rotating speed $(160 \mathrm{rpm})$ was maintained throughout the entire analysis except for $920 \mathrm{rpm}$ in the first $10 \mathrm{~s}$ to disperse sample. Each sample was analyzed in duplicate. The results were expressed in Rapid Visco Analyser units (RVU, 1 RVU $=12$ centipoises).

\subsection{Rheological Measurements}

Samples from the RVA were cooled to $25^{\circ} \mathrm{C}$, equilibrated overnight, and loaded on a rheometer (AR 2000, TA Instruments, New Castle, DE, USA) with a $6 \mathrm{~cm}$ diameter parallel acrylic plate with $1 \mathrm{~mm}$ gap to the surface. The outer edge of the plate was sealed with a thin layer of mineral oil (Sigma Chemical Co., St Louis, MO, USA) to prevent dehydration during the test. All rheological measurements were carried out at $25^{\circ} \mathrm{C}$ using a water circulation system within $\pm 0.1^{\circ} \mathrm{C}$. A strain sweep experiment was conducted initially to determine the limits of linear viscoelasticity; and then a frequency sweep test was carried out to obtain storage modulus $\left(\mathrm{G}^{\prime}\right)$ and loss modulus (G") at frequencies from 0.1 to $10 \mathrm{rad} \mathrm{s}^{-1}$ using a fresh sample. A strain of $0.5 \%$, which was within the linear viscoelastic range, was adopted for the dynamic experiments. The steady shear viscosity of the paste was measured as a function of shear rates from 1 to $100 \mathrm{~s}^{-1}$. The steady shear measurements apply varying steady shear deformation on sample material, with magnitude of each deformation depending on user-specified shear rates. All rheological measurements for samples were performed in duplicate.

\subsection{Dietary Fiber Assay}

The enzymes for assay were provided by Megazyme (Megazyme International, Ireland). The determination for dietary fiber is based on the methods of Lee et al. (1999) and Prosky et al (1998) with minor modification.

\subsection{Statistical Analysis}

Data from replicated samples were analyzed by SAS (Cary, NC) software using analysis of variance with Duncan's multiple comparison adjustment to determine significant differences $(P<0.05)$ between treatments (SAS Institute, 1999).

\section{Results}

\subsection{Water-Holding Capacity}

Water-holding capacity (WHC) is an important physical property of food products. Even at very low temperatures, absorbed water influences the mechanical performance in unexpected ways (Baschek et al., 1999). The water-holding capacities (WHC) of the starting materials and their composites are shown in Fig. 1. Overall, the WHC of amaranth-oat composites were all higher than that of amaranth (128.02\%). The composites blended with cold water had the highest water-holding capacity (724.73\%) whereas the composite processed using Polytron with cold water had the second highest WHC (607.7\%) among all the samples tested. The shearing forces of blending to promote molecular breakdown that contributed to increased water absorption. Interestingly, the WHC of the composite using Polytron with hot water was only about half of the WHC for the composite using Polytron with cold water. Water is considered to be active only when attached to polymer chains by hydrogen bonds. The properties can be changed by water in different ways at low and high temperatures (Baschek et al., 1999). The possible reason is that heat may denature a protein by disrupting hydrophobic and hydrogen bonds, resulting in reducing WHC by Polytron with hot water. Amaranth-oat composites can be widely used in different applications in the food industry because of their ability to retain water compared to amaranth flour alone, also notable for their thickening and gelling properties, synthesis control, and emulsion stabilization. 


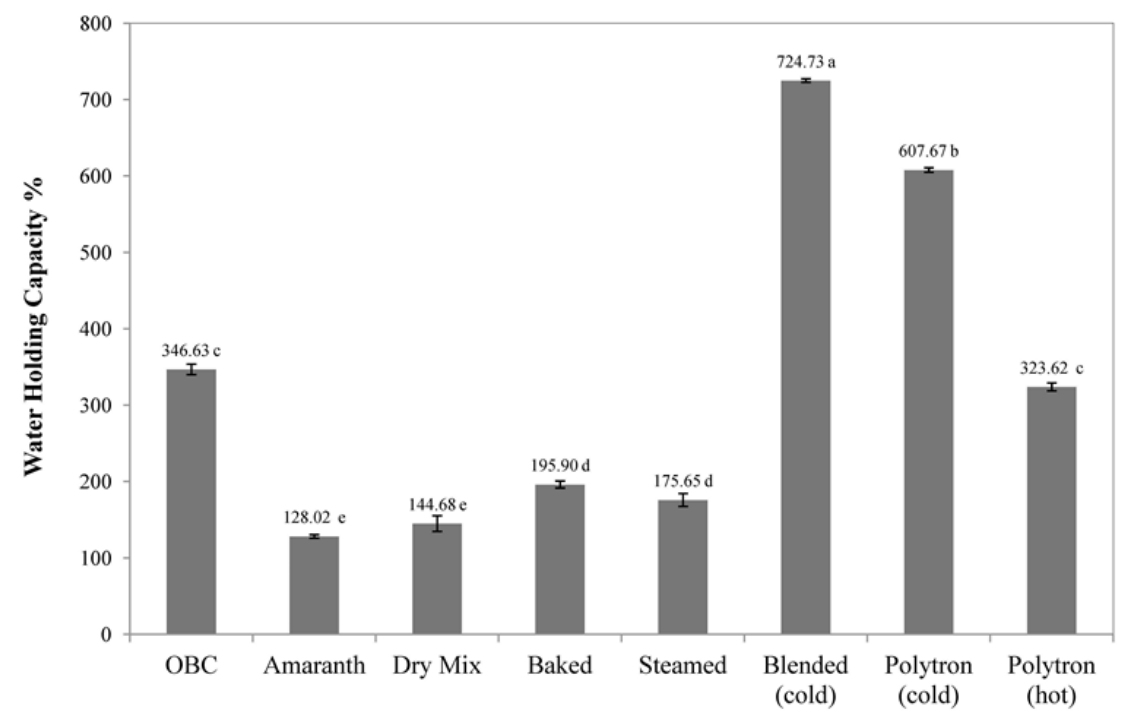

Figure 1. Water holding capacity of amaranth, oat, and processed amaranth and oat bran composites

\subsection{RVA Pasting Properties}

As shown in Fig.2, the pasting curves of all samples had dissimilar patterns indicating different pasting properties. The viscosity of OBC increased gradually $(\sim 7 \mathrm{RVU} / \mathrm{min})$ to the initial peak $(\sim 100 \mathrm{RVU})$ after the temperature reached $95^{\circ} \mathrm{C}$, remaining nearly constant viscosity during heating, and then increased sharply $(\sim 10$ RVU/min) during cooling resulting in the highest final viscosity ( $210 \mathrm{RVU})$ among all samples. The OBC viscosity increasing during the heating and shearing which is possibly due to starch gelatinization and interaction with $\beta$-glucan in $\mathrm{OBC}$, resulting in an entanglement of molecules during cooling. This high final viscosity indicated the matrix formation with greater stability under heat and shear. The steamed composite had the highest sharp initial peak ( $\sim 84 \mathrm{RVU})$ at $95^{\circ} \mathrm{C}$ among composites. The high initial peak suggested starch gelatinization of composites. The initial peaks of dry mixed $(\sim 55)$ and amaranth flour $(\sim 50)$ composites were lower than the steamed composite ( $\sim 84 \mathrm{RVU})$. The viscosity pattern from the steamed composite was similar to dry mixed and amaranth flour. The pasting curve for baked composite was increased during heating, and reached the same high final peak as steamed composite. No sharp initial peak was observed for baked composite as observed for steamed and dry mixed composites. It may be caused by heating over $100^{\circ} \mathrm{C}$ baking temperature, causing denatured protein or changed structures of starch, and influencing starch gelatinization. For blended composites with cold water, the pasting curve increased gradually during heating reaching a final peak $(\sim 81$ RVU). The final peak ( $~ 81 \mathrm{RVU})$ of blended composites with cold water was slightly lower than the steamed ( $97 \mathrm{RVU})$ and the baked ( $95 \mathrm{RVU})$ composites but it was higher than the composite using Polytron with cold water (23 RVU) and hot water (5 RVU). No visual distinguishing initial peaks were observed for composites by blender and Polytron. The high shearing by blender or Polytron may break hydrogen bounds and denature proteins resulting in low initial viscosities. Also, the composites using blender and Polytron were drum dried. It is known that the viscosity of completely gelatinized starch slurry will not increase during heating (Guha et al. 1998). The viscosity of amaranth showed the initial peak $(\sim 50 \mathrm{RVU})$ at $95^{\circ} \mathrm{C}$, and then the viscosity was kept constant until reached a final viscosity ( $\sim 57 \mathrm{RVU})$. Overall, all composites had higher final viscosities than that of amaranth, in exclusion of composites using Polytron. The high final viscosities most likely were caused by the beta glucan in OBC. The high final viscosities could be related to the stability of products after heating. These results suggested that those composites would be suitable for food products receiving heating and shearing treatments.

Improvement in the textural properties of food using oat $\beta$-glucan hydrocolloids has been reported (Inglett et al., 2014). The RVA data can provide useful information for food processing and product development. Composites with low pasting viscosity can be used in food formulations, such as beverages or instant porridge. Composites with high viscosity may be suitable for products with improved texture quality and health benefits, such as breads, nutritional bars, muffin, and cookies. 


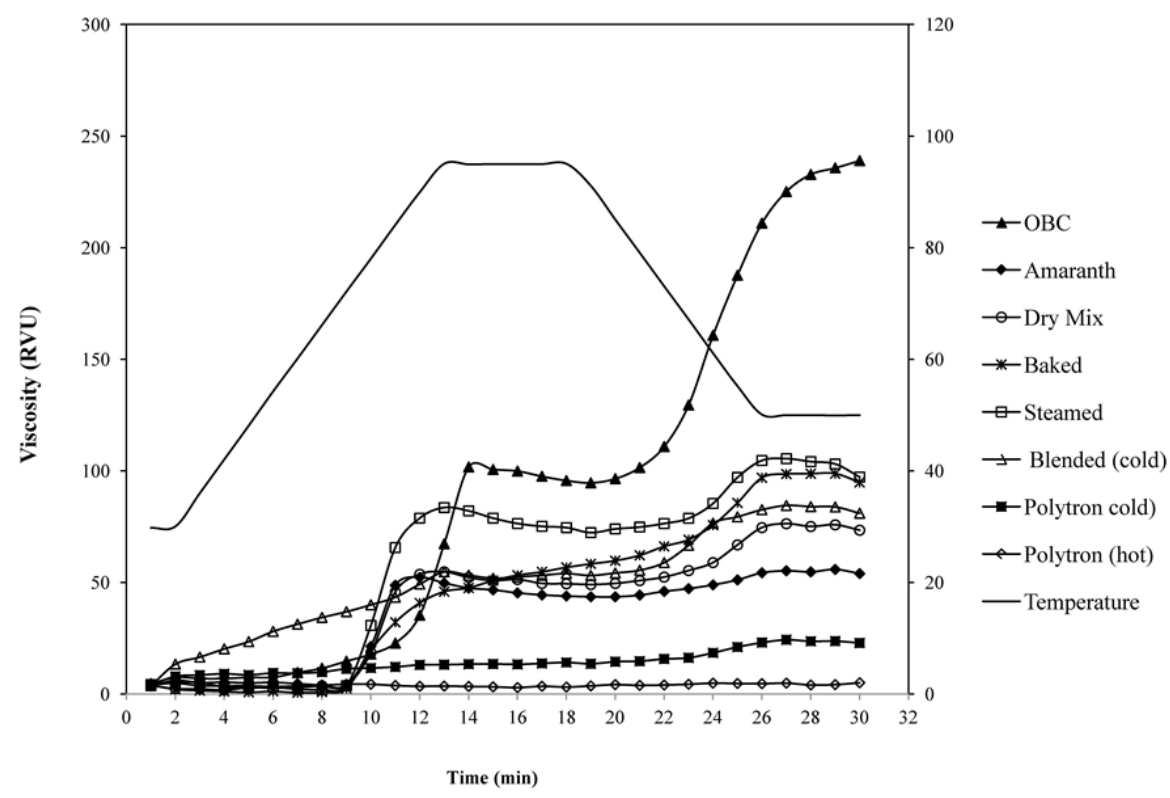

Figure 2. Pasting curve of amaranth, oat and processed amaranth-oat composites

\subsection{Rheological Properties}

The dynamic viscoelastic properties have been related to the product quality (Lee \& Inglett 2006). The G' and G" against frequency for all the sample materials are displayed in Fig. 3. The G', an elastic (storage) modulus, represents the non-dissipative component of the mechanical properties of a material and reflects its elastic characteristics. On the other hand, the viscous (loss) modulus ( $\left.\mathrm{G}^{\prime \prime}\right)$ characterizes the dissipative part of the mechanical properties and represents the viscous flow of the material. The moduli ( $G^{\prime}$ and $\left.G^{\prime \prime}\right)$ of all samples exhibited slight frequency dependence, representing the gel properties of samples. Moreover, all elastic moduli $\mathrm{G}^{\prime}$ were greater than viscous $\mathrm{G}^{\prime \prime}$ throughout the measured frequency range at different levels implying more solid-like behaviors, with the exception of the composites using Polytron with hot water (Fig.3). Particularly, the large differences between $G^{\prime}$ and $G^{\prime \prime}$ were observed for OBC, which suggested that the material should be classified rheologically as elastic gels (Lee \& Inglett 2006; Lai \& Cheng, 2004). It is known that if $G^{\prime}>G^{\prime \prime}$, the materials exhibited a viscoelastic solids behavior and the deformation on the linear range will be essentially elastic or recoverable (Gravier et al., 2004). The highest storage G' and loss G" moduli values were observed for $\mathrm{OBC}$ among all samples, indicating $\mathrm{OBC}$ had the greatest viscoelastic properties, which were contributed by the network forming with strong amylose and amylopectin interactions of OBC. The elastic (storage) and viscous (loss) moduli of steamed and baked composites are nearly identical, suggesting similar rheological properties. Also, elastic (storage) moduli of steamed and baked composites were higher than other composites, suggesting they have greater elastic properties than the remaining composites. Both $\mathrm{G}^{\prime}$ and $\mathrm{G}^{\prime \prime}$ for the composites using Polytron with hot water were considerably lower than other composites; the curves of the moduli were more frequency dependent; and the G" were higher than G' at high frequencies. This implied that the composites using Polytron with hot water exhibited viscoelastic fluid behaviors. The hydrothermal shearing by Polytron resulted in breaking down hydrogen bonds. Overall, elastic modulus $G^{\prime}$ for the steamed, baked, dry mixed, and blended composites were all higher than that for amaranth flour, with the exclusion of two composites using Polytron. It suggested that the elastic behaviors of amaranth-OBC composites were improved by OBC.

Furthermore, these rheological patterns of the amaranth-oat composites were clearly described by the $\tan \delta$ values (loss modulus G"/storage modulus G') (Fig. 4). The values of $\tan \delta$ indicate the ratio of energy lost to the amount of energy stored during a test cycle. The phase shift $\delta$ is defined by $\delta=\tan ^{-1}\left(G^{\prime \prime} / G^{\prime}\right)$, which indicates whether a material is solid $\left(\delta=0^{\circ}\right)$, liquid $\left(\delta=90^{\circ}\right)$, or between $\left(0^{\circ}<\delta<90^{\circ}\right)$. Therefore, the values of $\tan \delta$ are from zero to infinity; and $\tan \delta=1$ means $\mathrm{G}^{\prime}=\mathrm{G}^{\prime \prime}, \tan \delta<1$ represents $\mathrm{G}^{\prime}>\mathrm{G}^{\prime \prime}$, and $\tan \delta>1$ indicates $\mathrm{G}^{\prime}<\mathrm{G}^{\prime \prime}$. The $\tan \delta$ has been used for food products to indicate the strong relationship between the viscous behavior and the degree of casein hydrolysis (Gravier et al. 2004). Except the composite using Polytron with hot water, all $\tan \delta$ values were smaller than 1 , representing elastic properties over viscous properties ( $\left.G^{\prime}>G^{\prime \prime}\right)$. The $\tan \delta$ values of amaranth and amaranth-OBC composites were also slightly increased with frequencies. Specially, $\tan \delta$ values for the composites using Polytron with hot water increased considerably with increased frequencies (Fig.4), representing more viscous behaviors than elastic properties at higher frequencies. In contrast, $\tan \delta$ was 
decreased with increasing frequency for OBC (Fig.4). This elastic property of OBC was contributed by the components and structures of OBC. Tan $\delta$ of steamed and baked amaranth-OBC composites were lower than amaranth flour, indicating improved elastic properties by $\mathrm{OBC}$ and amaranth interactions. The enhanced elastic property can provide better shape retention during cooking and handling.

The apparent viscosities of the samples verses shear rate were illustrated in Fig. 5. Non-linear Rheological properties of food products, specifically apparent viscosity, have been used as references for predicting their processing performance. Most food processing and mastication occur in a shear rate range of 1 to $100 \mathrm{~s}^{-1}$ (Bloksma, 1998). All of the samples exhibited shear thinning behavior over the entire measured shear rates at $25^{\circ} \mathrm{C}$; the apparent viscosities of amaranth, $\mathrm{OBC}$ and its composites were decreased with the shear rate (Fig.5). Shear-thinning behavior can be observed in many food materials such as soy, rice, and wheat flour. This type of shear-thinning behavior can be attributed to the disruption of random coil polymers and/or their parallel alignment alone with flow stream during shearing (Salamone, 1996). The OBC had the highest apparent viscosity while the composite using Polytron with hot water had the lowest apparent viscosity. All composites had higher apparent viscosity than amaranth with the exceptions of composites prepared with Polytron. The apparent viscosities of baked, steamed, and blended composites were very close to each other suggesting those composites could have a similar thickening-effect in food processing (Fig.5). Shear-thinning behaviors of materials have several potential advantages in food applications. This behavior is favorable in industrial operations such as mixing and pumping. In addition, it was reported that the polysaccharide solutions in which viscosity decreases rapidly at shear rates are easily and quickly swallowed (Szczesniak \& Farkas, 1962). Hence, the shear-thinning behavior can contribute to a light and non-slimy mouthfeel for food products.

The rheological trends of the samples were in agreement with the RVA data (Fig.2 \& Fig 5). Because the experimental conditions we adopted were similar to actual processing situations, all our findings on rheological characteristics could be beneficial for processing and developing amaranth-OBC composites for new food applications.

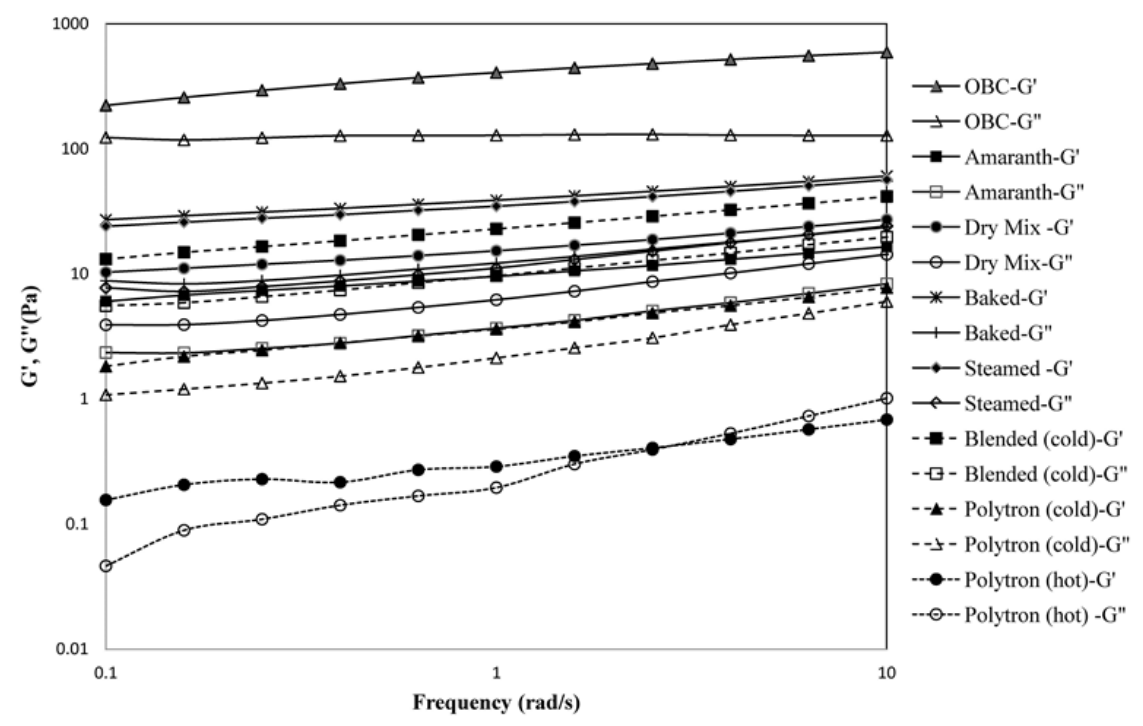

Figure 3. Dynamic viscoelastic properties of amaranth, oat and processed amaranth-oat composites 


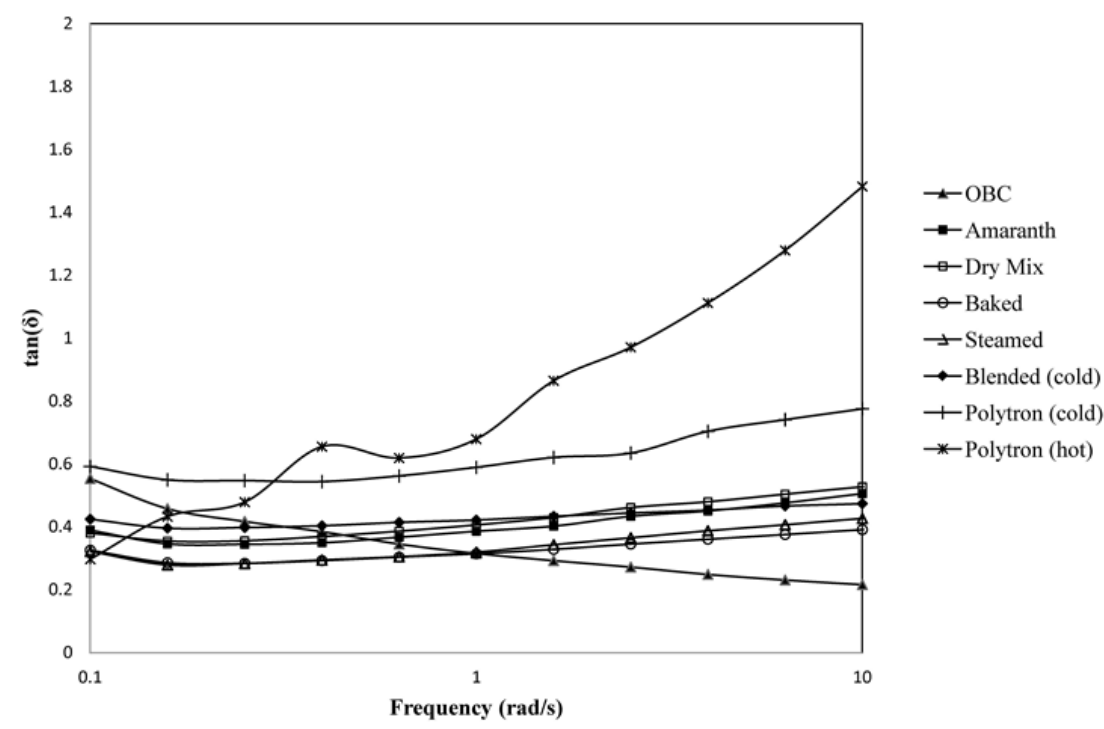

Figure 4. Values of $\tan \delta$ versus frequency ( $\mathrm{rad} / \mathrm{s})$ for amaranth, oat and processed amaranth-oat composites

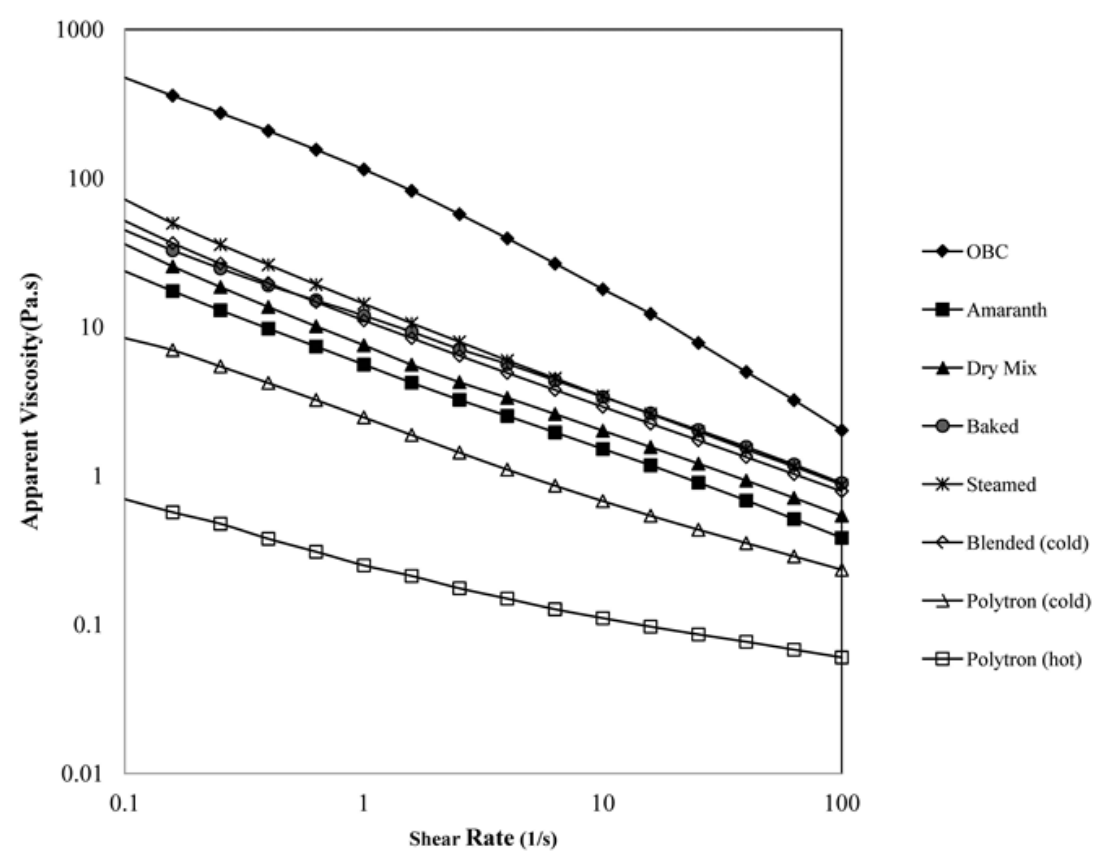

Figure 5. Apparent viscosity versus shear rate for amaranth, oat and processed amaranth-oat composites

\subsection{Dietary Fiber Content}

Of the under-consumed nutrients, calcium, potassium, dietary fiber, and vitamin D are considered nutrients of public health concern because low intakes are associated with health concerns (Health and Human Services Dept. and Agriculture Dept., 2015). In the United States, the recommended dietary fiber intake is $14 \mathrm{~g} / 1,000 \mathrm{kcal}$. For an average adult, this means a daily intake of $25 \mathrm{~g}$ (female) or $38 \mathrm{~g}$ (male). Most Americans only consume about half of the recommended intake (13.5 and $18 \mathrm{~g}$, respectively). This shortage in our diet is called the fiber gap.

The dietary fiber contents of composites were displayed in Table 1 . The dietary fiber ranged from $8.85 \%$ to $10.25 \%, 4.83 \%$ to $5.50 \%$, and 14.09 to $15.95 \%$ for insoluble, soluble, and total dietary fiber, respectively. The steamed composite had the highest insoluble $(10.25 \%)$ and total $(15.35 \%)$ dietary fiber content whereas dry mixed composite had the highest soluble dietary fiber (5.50\%) among all composites. The dry mixed composites and the steamed composites were processed with temperature under $100{ }^{\circ} \mathrm{C}$. The volatized compounds of dietary 
fibers in dry mixed and steamed composites will not be lost as baked composites at $375^{\circ} \mathrm{C}$. The total dietary fiber contents for composites using blender and Polytron with cold or hot water were slightly lower than steamed composites. Some dietary fibers may be lost on the hot drum at $135^{\circ} \mathrm{C}$ during drum drying. The effect of different heating methods on dietary fiber content was reported previously (Angrade et al., 2014). Amaranth contains about $6.7 \%$ of total dietary fiber (USDA Nutrition Database, 2017). OBC contained $12.4 \%$ soluble fiber beta glucan (Kim et al. 2008). Thus, dietary fibers contents in composites were greatly improved by the addition of oat bran concentrate.

Table 1. Dietary fiber contents of composites

\begin{tabular}{lccc}
\hline Treatment & Insoluble (\%) & Soluble (\%) & Total \\
\hline Dry Mix & $8.85 \pm 0.06^{\mathrm{b}}$ & $5.50 \pm 0.05^{\mathrm{a}}$ & $14.36 \pm 0.01^{\mathrm{b}}$ \\
Baked & $9.45 \pm 0.42^{\mathrm{b}}$ & $4.83 \pm 0.16^{\mathrm{c}}$ & $14.65 \pm 0.58^{\mathrm{ab}}$ \\
Steamed & $10.25 \pm 0.35^{\mathrm{a}}$ & $4.96 \pm 0.04^{\mathrm{bc}}$ & $15.35 \pm 0.31^{\mathrm{a}}$ \\
Blended & $9.18 \pm 0.11^{\mathrm{b}}$ & $5.22 \pm 0.37^{\mathrm{abc}}$ & $14.39 \pm 0.48^{\mathrm{b}}$ \\
Cold Polytron & $9.01 \pm 0.20^{\mathrm{b}}$ & $5.31 \pm 0.01^{\mathrm{ab}}$ & $14.35 \pm 0.20^{\mathrm{b}}$ \\
Hot Polytron & $8.90 \pm 0.25^{\mathrm{b}}$ & $4.99 \pm 0.03^{\mathrm{bc}}$ & $14.09 \pm 0.21^{\mathrm{b}}$ \\
\hline
\end{tabular}

Means \pm standard deviation; $\mathrm{n}=3$; means followed by the same letter within the same column are not significantly different $(P>0.05)$.

\section{Conclusion}

Amaranth-oat composites combined the oat soluble fiber $\beta$-glucan from oat bran and special amino acids of amaranth along with gluten free quality. Amaranth flour and oat bran concentrate (OBC) composites (1:4) processed with different technologies revealed some interesting physical properties. The results showed that water holding capacities, pasting, and rheological properties were dramatically increased by wet blended, cold wet Polytron, hot wet Polytron followed by drum drying. Also, the different processing procedures created dissimilar functional properties for enhancing various nutritional food applications, such as bakery, beverage, and instant porridge. These composites were prepared using simple and low-cost procedures and methods. It is predicted that the costs of these new commercial products would not be expensive for people having celiac disease, other gluten-intolerance, and poor diet. Innovated gluten-free functional food products could potentially impact millions of Americans' health and wellbeing who are sensitive to gluten; this in turn can potentially help reduce the increase in medical care costs.

\section{References}

Ade-Omowaye, B. I. O., Taiwo, K. A., Eshtiaghi, N. M., Angersbach A., \& Knorr, D. (2003). Comparative evaluation of the effects of pulsed electric field and freezing on cell membrane permeabilisation and mass transfer during dehydration of red bell peppers. Innovative Food Sci. Emerging Technol, 4, 177-188. https://doi.org/10.1016/S1466-8564(03)00020-1

Andrade J. M. M., de Jong, E. V., \& Henriques A. T. (2104). Byproducts of orange extraction: influence of different treatments in fiber composition and physical and chemical parameters. Brazilian Journal of Pharmaceutical Sciences, 50. https://doi.org/10.1590/S1984-82502014000300005

Ayo, J. A. (2001). The effect of amaranth grain flour on the quality of bread. International Journal of Food Properties, 4, 341-351. https://doi.org/10.1081/JFP-100105198

Baschek, G., Hartwig, G., \& Zahradnik, F. (1999). Effect of water absorption in polymers at low and high temperatures. Polymer, 40, 343-3441. https://doi.org/10.1016/S0032-3861(98)00560-6

Bloksma, A. (1988). Rheology of the bread making process. Paper presented at $8^{\text {th }}$ International Cereal and Bread Congress. Lausanne, Switzerland.

Bressani, R., Elias, G. L., \& Garcia-Soto, A. (1989). Limiting amino acids in raw and processed amaranth grain protein from biological tests. Plant foods for human nutrition (Kluwer Academic Publishers), 39, 223-234. https://doi.org/10.1007/BF01091933

Czerwiński, J., Bartnikowska, E., \& Leontowicz, H. (2004). Oat (Avena sativa L.) and amaranth (Amaranthus hypochondriacus) meals positively affect plasma lipid profile in rats fed cholesterol-containing diets. J. Nutr. Biochem, 15, 622-629. https://doi.org/10.1016/j.jnutbio.2004.06.002

Gallagher, E., Gormley, T. R., \& Arendt, E. K. (2004). Recent advances in the formulation of gluten-free cereal-based products. Trends in Food Science \& Technology, 15, 143-152. 
https://doi.org/10.1016/j.tifs.2003.09.012

Gravier, N. G., Zaritzky, N. E., \& Califano, A. N. (2004). Viscoelastic behavior of refrigerated and frozen low-moisture Mozzarella cheese. J. Food Science, 9, 123-128. https://doi.org/10.1111/j.1365-2621.2004.tb13364.x

Guha, M., Zakiuddin, A. S., \& Bhattacharya, S. (1998). Effect of barrel temperature and screw speed on rapid viscoanalyser pasting behaviour of rice extrudate. International Journal of Food Science and Technology, 3, 259-266. https://doi.org/10.1046/j.1365-2621.1998.00189.x

Health and Human Services Dept. and Agriculture Dept. (2015). Dietary Guidelines for American 2015-2020. (8 $8^{\text {th }}$ edition). https://health.gov/dietaryguidelines/2015/guidelines/

Prosky, L., Asp, N. G., Schweizer, T. F., DeVries, J. W., \& Furda, I. (1992). Determination of insoluble and soluble dietary fiber in foods and food products: Collaborative study. Journal of the Association of Official Analytical Chemists, 75, 360-367.

Inglett, G. E., Diejun, Chen, \& Sean, X. Liu. (2014). Properties of Amaranth Flour With Functional Oat Products. Journal of Food Research, 3(6). https://doi.org/10.5539/jfr.v3n6p1

Inglett, G. E., \& Chen, D. (2012). Antioxidant and pasting properties of oat B-glucan hydrocolloids. Food and Nutrition Sciences, 3, 827-835. https://doi.org/10.4236/fns.2012.36111

Inglett, G. E., Chen, D., \& Berhow, M. (2011). Influence of jet cooking Prowashonupana barley flour on phenolic composition, antioxidant activities, and viscoelastic properties. Cereal Chemistry, 88, 315-320. https://doi.org/10.1094/CCHEM-10-10-0150

Kaufmann, C. S., \& Weber, L. E. (1990). Grain amaranth. In J. Janick \& J. E. Simon (Eds.), Advances in New Crops (pp. 127-139). Timber Press, Portland, Oregon, USA.

Kim, S., Inglett, G. E., \& Liu, S. X. (2008). Content and molecular weight distribution of oat $\beta$-glucan in oatrim, nutrim, and C-trim products. Cereal Chemistry, 85, 701-705. https://doi.org/10.1094/CCHEM-85-5-0701

Klopfenstein, C. F. (1988). The role of cereal beta-glucans in nutrition and health. Cereal Food World, 33, 865-869.

Lai, H. M., \& Cheng, H. H. (2004). Properties of pregelatinized rice flour made by hot air or gum puffing. International Journal of Food Science and Technology, 39, 201-212. https://doi.org/10.1046/j.0950-5423.2003.00761.x

Lee, M. H., Baek, M. H., Cha, D. S., Park, H. J., \& Lim, S. T. (2002). Freeze-thaw stabilization of sweet potato starch gel by polysaccharide gums. Food Hydrocolloids, 16, 345-352. https://doi.org/10.1016/S0268-005X(01)00107-2

Lee, S. C., Prosky, L., \& DeVries, J. W. (1992). Determination of total, soluble, and insoluble, dietary fiber in foods - enzymatic- gravimetric method, MES-TRIS buffer: Collaborative study. Journal of the Association of Official Analytical Chemists, 75, 395-416.

Lee, S., \& Inglett, G. E. (2006). Rheological and Physical evaluation of jet-cooked oat bran in low calorie cookies. International Journal of Food Science and Technology, 41, 553-559. https://doi.org/10.1111/j.1365-2621.2005.01105.x

Lee, S., Inglett, G. E., \& Carriere, C. J. (2004). Effect of nutrim oat bran and flaxseed on rheological properties of cakes. Cereal Chemistry, 81, 637-642. https://doi.org/10.1094/CCHEM.2004.81.5.637

Lee, S., Warner, K., \& Inglett, G. E. (2005). Rheological properties and baking performance of new oat $\beta$-glucan-rich hydrocolloids. Journal of Agricultural and Food Chemistry, 53, 9805-9809. https://doi.org/10.1021/jf051368o

Macvean, D., Pöll. (1997). Chapter 8: Ethnobotany. In J. A. Vozzo (Ed.) Tropical Tree Seed Manual, USDA Forest Service.

Madhujith, T., \& Shahidi, F. (2007). Antioxidative and antiproliferative properties of selected barley (Hordeum vulgare L.) cultivars and their potential for inhibition of low-density lipoprotein (LDL) cholesterol oxidation. Journal of Agricutlural and Food Chemistry, 55, 5018-5024.

Megazyme International Ireland. 2015. www.magazyme.com

Martirosyan, D. M., Miroshnichenko, L. A., Kulakova, S. N., Pogojeva, A. V., \& Zoloedov, V. I. (2007). Amaranth oil application for coronary heart disease and hypertension. Lipids Health Dis., 6(1). 
https://doi.org/10.1186/1476-511X-6-1

Myers, L. R., \& Putnam, H. D. (1988). Growing Grain Amaranth as a Specialty Crop. In Crop Systems. University of Minnesota. FS-03458-GO.

Pisarikova, B., Peterka, J., Trčková, M., Moudrý, J., Zralý, Z., \& Herzig, I. (2006). Chemical composition of the above-ground biomass of Amaranthus cruentus and A. hypochondriacus. Acta Veterinaria Brno, 75, 33-138. https://doi.org/10.2754/avb200675010133

Rosell, C. M., Rojas, J. A., \& Benedito de Barber, C. (2001). Influence of hydrocolloids on dough rheology and bread quality. Food Hydrocolloids, 15, 75-81. https://doi.org/10.1016/S0268-005X(00)00054-0

Salamone, J. C. (1996). Polymeric Materials Encyclopedia. CRC Press, Boca Raton, FL.

SAS Institute INC. (1999). The SAS ${ }^{\circledR}$ system for Windows ${ }^{\circledR}$, version 8e. Cary, NC.

Szczesniak, A. S., \& Farkas E, (1962). Objective characterization of the mouthfeel of gum solutions. J. Food Sci., 27, 381-385. https://doi.org/10.1111/j.1365-2621.1962.tb00112.x

USDA Nutrient Database. (2014). http://ndb.nal.usda.gov/ndb/foods/show/6238

\section{Copyrights}

Copyright for this article is retained by the author(s), with first publication rights granted to the journal.

This is an open-access article distributed under the terms and conditions of the Creative Commons Attribution license (http://creativecommons.org/licenses/by/3.0/). 